\title{
Editorial
}

\section{Moving toward More Frequent On-Line Only Journal}

From January 2019, Korean Journal of Radiology (KJR) publishes every month. Rapid publication of excellent accepted articles is very important, while decisions on submitted papers should be made as soon as possible. KJR will not publish printed issues at the same time. Practically, readers of KJR can access the journal on line freely. Reading printed journals becomes a legacy. KJR also pursues to publish articles electronically ahead of the designated issues to provide readers latest information on radiology, as soon as the proof of papers finishes.

KJR has been increasingly cited by articles and journal impact factor is rising continuously. We are expecting the increase in numbers of submissions as well as the increase in the number of articles published in the year 2019.

We look forward to your contribution to KJR.

Yeon Hyeon Choe, MD, PhD Editor-in-Chief 